\title{
A primeira resenha portuguesa sobre A educação pela pedra, de Arnaldo Saraiva, antecedida por uma apresentação
}

\author{
The first portuguese review about Education \\ by stone, by Arnaldo Saraiva, preceded \\ by an introduction
}

Solange Fiuza ${ }^{1}$

Waltencir de Oliveira ${ }^{2}$

RESUMO

O crítico português Arnaldo Saraiva leu A Educação pela Pedra quando de seu lançamento e publicou, em 27 de agosto de 1966, no Correio da Manhã, do Rio de Janeiro, uma resenha sobre o livro, republicada, em 1967, no Diário de Notícias, de Lisboa. Este trabalho contém uma apresentação da resenha, seguida do texto resenhado.

Palavras-chave: João Cabral de Melo Neto; Arnaldo Saraiva; A Educação pela Pedra; crítica portuguesa.

\section{ABSTRACT}

The Portuguese critic Arnaldo Saraiva read Education by Stone when it debuted and published, on August 27, 1966, in the newspaper Correio da Manhã, from Rio de Janeiro, a review about the book, republished in 1967 in the Diário de Notícias, from Lisbon. This work contains an introduction to the review, followed by the text.

Keywords: João Cabral de Melo Neto; Arnaldo Saraiva; Education by Stone; Portuguese critique.

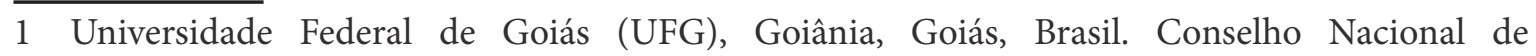
Desenvolvimento Científico e Tecnológico (CNPq).E-mail: solfiuza@gmail.com

2 Universidade Federal do Paraná (UFPR), Curitiba, Paraná, Brasil. E-mail: waltenciroli@gmail. com 


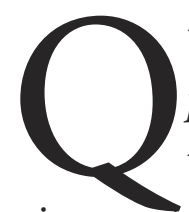

uando João Cabral de Melo Neto publicou, no Brasil, A Educação rios poetas portugueses. A edição princips de Quaderna ${ }^{3}$ saiu em 1960 pela Guimarães Editores, com curadoria de Alexandre O’Neill, que foi também o responsável pela seleção dos poemas que integrariam os Poemas Escolhidos, antologia publicada pela Portugália, em 1963, com apresentação de Alexandre Pinheiro Torres. Esses livros, sobretudo a antologia, tiveram um importante papel na difusão do poeta em Portugal e suscitaram resenhas de alguns dos mais importantes críticos portugueses de então, como João Gaspar Simões, Óscar Lopes e Eduardo Prado Coelho. Também Cabral, com sua poesia simultaneamente empenhada e formalmente tensa, foi uma referência tanto para poetas sensíveis às demandas do Neorrealismo português quanto para os que buscavam caminhos mais experimentais. $\mathrm{O}$ caso mais expressivo e produtivo nesse sentido foi o de Sophia de Melo Breyner Andresen, que, por sua vez, era considerada, por Cabral, "o maior poeta" de sua geração em Portugal. Além disso, as apresentações do poema dramático Morte e Vida

3 Quaderna foi publicado no Brasil em 1961, na reunião Terceira Feira. 
Severina pelo grupo TUCA, realizadas em 1966 em Lisboa, Porto e Coimbra, logo após a premiação recebida pelo grupo no IV Festival de Teatro Universitário de Nancy, divulgou o poeta junto a um público mais amplo, além de ter suscitado várias resenhas.

Nesse cenário já preparado, quando o poeta publicou, no Brasil, $A$ Educação pela Pedra, o livro, pela sua ordem de dificuldade, não alcançou, em Portugal, um público tão amplo quanto o auto de Natal, mas foi apreciado criticamente por leitores especialistas, entre os quais Arnaldo Saraiva, o primeiro crítico português do livro.

O primeiro contato mais efetivo de Arnaldo Saraiva com Cabral se deu quando da publicação de Quaderna. Segundo o crítico, conhecendo três ou quatro poemas de Cabral, teria tomado consciência de que se tratava de um poeta de exceção quando, calouro na Faculdade Letras da Universidade de Lisboa, pôde ler o livro publicado pela Guimarães Editores (SARAIVA, 2014, p. 95). Depois disso, quando estava no Brasil desenvolvendo uma investigação sobre Carlos Drummond de Andrade, assistiu, no Rio de Janeiro, à apresentação de Morte e Vida Severina pelo TUCA e, impactado pelo espetáculo, enviou uma resenha para publicação no Jornal de Letras e Artes, de Lisboa. Ainda no Rio, leu A Educação pela Pedra quando de seu lançamento e publicou, em 27 de agosto de 1966, no Correio da Manhã, do Rio de Janeiro, uma resenha sobre o livro intitulada "A Educação (poética) pela Pedra”. Nessa resenha, republicada, em 1967, no Diário de Notícias, de Lisboa, com o título "O último livro de João Cabral de Melo Neto"4, o argumento central é a dificuldade de leitura imposta pela obra.

200 A recusa da facilidade, que implica, naturalmente, a criação de dificuldades ou resistências, estaria, segundo o crítico, sobretudo, nas constantes violências sintáticas; na exclusividade concedida ao verso longo, de 10,11, 12 e mais sílabas, "muito mais pesado ou 'resistente' que o verso curto" predominante na poesia anterior; no uso acumulado de símbolos, aos quais o poeta se esforça por dar uma configuração concreta; e no "rigoroso esquema" do livro (SARAIVA, 1966, p. 2)

Saraiva descreve e exemplifica cada um dos indicadores da dificuldade do livro. Mas interessa destacar uma discreta e dubitativa reserva feita por ele ao rigor posto na estrutura da obra, ao seu "geometrismo", quando diz que, com esse geometrismo, o poeta teria querido, "talvez sem grande resultado, transformar os diversos poemas em um mesmo poema” e por conta disso teria repetido "ipsis verbis dois ou três poemas (alterando apenas a ordem dos versos e do título)".

\footnotetext{
4 A resenha, juntamente com outros trabalhos éditos e inéditos de Saraiva sobre Cabral, foi reunida em 2014 no livro Dar a Ver e a se Ver no Extremo: o Poeta e a Poesia de João Cabral de Melo Neto.

5 Todas as demais citações da resenha, transcrita após esta apresentação, apresentam essa mesma referência.
} 
A. SARAIVA

S. FILUZA

W. Oliveira

A primeira resenha portuguesa sobre A educação pela pedra, de Arnaldo

Saraiva,

antecedida por uma apresentação
Ler A Educação pela Pedra a partir da dificuldade de leitura estabelecida pelo livro, tomando essa dificuldade como critério de valor, ainda hoje é uma constante na recepção luso-brasileira do poeta, mas talvez o tenha sido ainda mais quando das primeiras recepções, por conta da voga do formalismo e do estruturalismo e de vanguardas como a Poesia Concreta. Nesse sentido, em resenha publicada uns quatro meses depois da de Arnaldo Saraiva, o poeta brasileiro Augusto de Campos também destaca, entre outros aspectos, o caráter "[d]ifícil e exigente" do livro, a "exigir do leitor [...] não 'atos de imolação', mas 'atos complexos de discernimento"' (CAMPOS, 1978, p. 50).

Mas enquanto Augusto de Campos toma a dificuldade do livro e o consequente afastamento do leitor como um valor tout court, associando, numa equação simplificadora, "êxito comunicativo" com fracasso poético, e "fracasso comunicativo" com "êxito da poesia", Arnaldo Saraiva vê uma grande virtude na boa poesia que logra comunicação com um público mais amplo. Antes da resenha de A Educação pela Pedra, na já mencionada resenha sobre a apresentação de Morte e Vida Severina pelo TUCA, louva a sensibilização pública desse poema de "superior qualidade artística":

Nunca me fora dado assistir a uma representação teatral que resolvesse com tanta felicidade o aparente (e para muitos ainda real) dilema vanguarda-povo, que destruísse com tanta eficácia o mito (que é ainda de muitos) da incompatibilidade entre a superior qualidade artística e a comunicação com o grande público. (SARAIVA, 1966, p. 5)

A dificuldade de A Educação pela Pedra descrita por Arnaldo Saraiva no momento da publicação do livro, e hoje convertida em verdadeiro truísmo pela crítica cabralina, certamente não desagradou a Cabral na ocasião. $\mathrm{O}$ próprio Saraiva (2014, p. 98), em recordações do amigo poeta, conta que este muitas vezes o saudava com as palavras iniciais da primeira resenha: "Eis um livro que custa os olhos da cara".

A dificuldade vista como um valor poético, como algo que deve ser deliberadamente criado pelo poeta para obstar a leitura "fluviante, flutual", encontra-se teorizada no poema "Catar feijão" à maneira de uma exortação poética. Considerando a dimensão crítica desse e de vários poemas do livro, Saraiva declara em um dos parágrafos finais da resenha: "Em poucos versos, o grande poeta nordestino [...] faz a crítica que eu gostaria de ter feito ao longo destas linhas". Ou seja, os poemas críticos de A Educação pela Pedra constituem eles próprios a primeira leitura do livro; leitura que, de certa forma, orienta o argumento da resenha inaugural sobre ele em Portugal.

Se a Cabral não desagradou a ênfase de Saraiva na dificuldade do livro, talvez não se possa dizer o mesmo da discreta restrição do crítico ao
Revista Letras,

Curitiba, UFPR, n. 102, pp. 198-207,

jul./dez. 2020

ISSN 2236-0999

(versão eletrônica) 
seu "geometrismo", com o qual teria querido o poeta, nas palavras do crítico, "transformar, talvez sem grande resultado, os diversos poemas em um mesmo poema” (grifo nosso).

Cabral registra, em entrevistas, que A Educação pela Pedra é, "como estrutura", a sua obra mais tensa (ATHAYDE, 1998, p. 112), ou seja, aquela em que levou ao extremo o construtivismo, a concepção do livro como uma obra planejada e rigorosamente executada, conforme entende a partir de Psicologia da Composição. Tal seria o planejamento de A Educação pela Pedra que Antonio Carlos Secchin publicou, na edição da Colóquio/Letras que homenageia Cabral, uma "planta baixa" traçada pelo poeta. No caso de A Educação pela Pedra e já em livros anteriores, construtivismo quer dizer também obsessão pela simetria.

Esse construtivismo se refletiria ainda na composição dos poemas, numa reescrita insistente, sobre a qual há até uma espécie de anedotário divulgado pelo próprio poeta. Nesse sentido, Cabral declara, por exemplo, que teria escrito 48 versões de um dos poemas permutáveis de $A$ Educação pela Pedra, mas incluído duas (SECCHIN, 1999). Declara ainda que o antológico "Tecendo a manhã" teria lhe custado nove anos de trabalho (esse tempo varia de uma a outra entrevista), esclarecendo, entretanto, que não ficou esses anos escrevendo o poema, mas que começou a escrevê-lo, e, como ele não se encaixava na estrutura dos livros que ia publicando, ficou guardado, até que pôde ser inserido na obra cujos poemas se fundam numa estrutura binária (STEEN, 2008). "Tecendo a manhã" é exemplar não só do construtivismo dos poemas do livro, mas de uma subordinação dos poemas a uma organização estrutural, conforme era gosto do poeta.

Sobre esse construtivismo e essa prevalência da estrutura sobre os poemas individuais, o primeiro leitor português de A Educação pela Pedra, Arnaldo Saraiva, não demonstra muita empolgação, ou melhor, manifesta uma discreta e dubitativa reserva.

A crítica posterior tenderá, na esteira do próprio Cabral, a supervalorizar o construtivismo da obra. Considerado, entretanto, isoladamente, como um valor em si, sem o contraponto com os poemas individuais, esse construtivismo revela-se pouco produtivo e não dá conta de evidenciar a força de um livro como A Educação pela Pedra. Seriam precisos tempo, acúmulos e saturações críticos para que se realizassem leituras mais produtivas desse construtivismo, as quais revelassem suas tensões ou mesmo o relativizassem.

Arnaldo Saraiva, hoje professor emérito da Universidade do Porto, fundador, nos anos 1970, da cadeira de Literatura Brasileira na U. Porto, continuou acompanhando a produção de Cabral. Entrevistou o poeta em várias ocasiões, foi seu amigo, escreveu sobre ele vários estudos e hoje continua atuando como seu crítico ativo, tendo publicado, em 2014, em Portugal, o Dar a Ver e a se Ver no Extremo: o Poeta e a Poesia de João Cabral de Melo Neto, 
A. SARAiva livro em que reúne entrevistas e trabalhos éditos e inéditos e, ainda, acaba

S. FILUZA

W. Oliveira

A primeira resenha portuguesa sobre A educação pela pedra, de Arnaldo

Saraiva,

antecedida por uma apresentação de publicar um folheto sobre o poeta intitulado João Cabral de Melo Neto na Poesia Portuguesa (SARAIVA, 2020).

A resenha que o leitor lerá a seguir é, pois, não apenas a primeira sobre A Educação pela Pedra escrita por um crítico português, mas um dos primeiros trabalhos de um estudioso que, há mais de 50 anos, vem se dedicando a compreender a poesia de Cabral, a difundi-la em Portugal, bem como a servir a Literatura Brasileira e a torná-la conhecida junto ao público português. 


\title{
A Educação (Poética) pela Pedra
}

\author{
Arnaldo Saraiva ${ }^{6}$
}

$\mathrm{E}$

is um livro que custa os olhos da cara. Não pelo preço da capa, naturalmente; mas pelo preço que cobra ao leitor que pretenda possuí-lo: preço de atenção, de esforço intelectual, de coragem psíquica e até física. A Educação pela Pedra é, na verdade, um livro duro como a dita, áspero, dificílimo de ler. Um livro mastigado, mascado como os chiclets a que alude um poema. Dir-se-ia que João Cabral quis que a sua poesia fosse o contrário da publicidade, do panfleto, do slogan, que enchem o nosso tempo. Onde estes tentam simplificar, tenta ela complicar. O que estes procuram mostrar, procura ela esconder. Quando estes se esforçam por atrair, esforça-se ela por repelir.

Mas é evidente que esse complicar, esconder, repelir, corresponde a uma tentativa de simplificação, de exposição, de atracção outras. Uma tentativa inteligente de ler-por-dentro (intuslegere): de desprezar, ultrapassando-o, tudo o que é aparente e, aparecendo, reduz, ou encobre, ou engana, ainda quando verdadeiro. Como Fernando Pessoa, João Cabral jamais deixa de «estar pensando» quando sente. Ele mesmo declarou, há anos, a um pobre jornalista português: «a poesia faço-a como actividade fria e matemática». E ainda: «Tudo o que nasce com facilidade, rasgo-o».

A recusa a «ir na onda» da emoção ou da imaginação - ou da sociedade, ou dos poderes públicos, ou das modas, etc.: a ars poetica de João Cabral e, antes de mais, uma ars vivendi - a recusa intelectual da facilidade implica naturalmente certas dificuldades ou resistências, que se traduzem onomatopaicamente, ao nível linguístico, em asperezas expressionais, gagueiras estilísticas, obstruções melódicas, saltos sintácticos. A Educação pela Pedra está cheia de «onomatopeias».

Uma delas é o símbolo da pedra, que deu o título ao livro e que figura em vários poemas, como "Catar feijão» (A pedra dá à frase o seu grão mais vivo;/ obstrui a leitura fiuviante, flutual,/ açula a atenção, isca-a com o risco.), «O sertanejo falando» (As palavras de pedra ulceram a boca) e «The country of the houyhnhnms» (para falar dos yahoos se necessital que as palavras funcionem de pedra). Recordemos que os houyhnhnms eram cavalos cuja língua o herói de Jonathan Swift quis aprender, à custa de tremendos esforços.

Outra das «onomatopeias» está contida no poema «Num monumento à aspirina», que é a versão «complicada» do poema «Para um monumento à aspirina», publicado há dois ou três anos na revista Senhor e que, aliás, lhe era superior sob alguns aspectos. Dá a impressão que João Cabral refundiu o poema apenas para o inserir dentro do rigoroso esquema a que obedece o seu

6 Universidade do Porto, Porto, Portugal. E-mail: asaraiva@netcabo.pt. 
A. SARAIVA

S. FILUZA

W. Oliveira

A primeira resenha portuguesa sobre A educação pela pedra, de Arnaldo

Saraiva,

antecedida por uma apresentação

livro: quatro partes - $a, b, A, B$-, cada uma com 12 poemas, cada um com $16(a b)$ ou $24(A, B)$ versos, repartidos por duas estrofes, cujo tamanho varia de 3 em 3 poemas, de 8-8 versos, para 6-10, para 10-6, para 8-8 (a, b), ou de 12-12 versos para 8-16, para 16-8. Neste geometrismo, que certamente quis, talvez sem grande resultado, transformar os diversos poemas em um poema, e que levou o poeta a repetir ipsis verbis dois ou três poemas (alterando apenas a ordem dos versos e do título). Neste geometrismo, dizia, não estará mais um dado das dificuldades impostas ao autor e propostas ao leitor?

Mas a prova maior dessas dificuldades está na exclusividade que João Cabral concedeu ao verso longo $(10,11,12$ e mais sílabas: influência do «Mio Cid»?), muito mais pesado ou «resistente» do que o verso curto que predominava na sua poesia anterior, e sobretudo no aumento considerável de violências sintácticas que o livro acusa. Tantas e tais são que não me espantaria nada se, num próximo volume, João Cabral abandonasse o discurso e passasse a fazer uma poesia de tipo concretista, da qual está perto, como de resto já foi assinalado.

Não têm conto as figuras de sintaxe (e figuras são sempre «violências» de A Educação pela Pedra). Por exemplo: elipse (para que nada lhes escape/ na escolha entre o que a bandeja - subentenda-se "contém»; Só os banguês queainda - subentenda-se «existem»); zeugma (contêm nadas, contêm apenas vazios:/ o que a esponja, vazia quando plena); hipérbato (Então, fazem lembrar os de anatomista/ o método e os modos deles nessa mesa); anacoluto (Ao rio Beberibe, quando rio adolescente/ (precipitadamente tempo, não espaço)/ nada lhe pára os pés).

A esta altura já é admissível supor que todas as "violências» ou «obstruções» foram cometidas em favor do «adensar-se compacto» da linguagem, de que, em última análise, resultam todas as dificuldades de leitura. Tal ideia é absolutamente confirmada quando se atenta no uso que João Cabral também faz de certas figuras de pensamento, ou de determinados recursos morfo-semânticos. Por exemplo: enálage (adentros, quandos, agulhíssimos); dois pontos - que substituem o verbo ou a cópula (Insolúvel: na água quente e na fria); construções inusitadas (Os vazios do homem não sentem ao nada/ do vazio qualquer); hífen (nós-se-não-pregos; por-onde); compostos por prefixação (ingasto, desinflama, multiespinhenta); sufixação (agrestino, saberente: o autor chega a fazer permutas como fluviante, flutual); e, sobretudo, aglutinação (corpopulenta, fundassentados).

É, porém, no uso acumulado de símbolos que mais se denuncia esse «adensar-se compacto». O símbolo é a síntese por excelência, e por isso não admira que João Cabral o empregue tão frequentemente, apesar de a sua poesia ter uma feição nitidamente concreta; aliás, ele esforça-se sempre por dar uma configuração concreta aos símbolos, decompondo-os ou analisando- 
os em estratos, parcelas, séries, e dá clara preferência aos símbolos concretos, objetivos, como esse da pedra.

O que tem levado os homens de todos os tempos a escolherem a pedra como símbolo (sociedades primitivas, religiosas, filósofos, poetas: Dante, Camões, Pessoa, Guillevic, Drummond) é, de uma maneira geral, «la puissance, la dureté, la permanence» (Mircea Eliade) que ela parece espelhar. Mas João Cabral retirou dela, além desta lição de moral (sua resistência fria/ ao que flui e a fluir, e a ser maleada), outras lições: de poética (sua carnadura concreta), de economia (seu adensar-se compacta) e uma muito especial, «prédidáctica», que só é possível no sertão: «lá a pedra uma pedra de nascença, estranha a alma».

Em poucos versos, o grande poeta nordestino - e mais de $50 \%$ dos poemas do livro falam exclusivamente do Nordeste - fez a crítica que eu gostaria de ter feito ao longo destas linhas. Que elas tenham ao menos o mérito de chamar a atenção para um livro excepcional ou de homenagear um poeta que no Brasil, em Portugal, na Espanha, na Suíça, em qualquer parte do Mundo, deve ser hoje considerado como mestre.

Porque a «pedra» de João Cabral, à semelhança da pedra de Demóstenes e, da pedra de Drummond, pode curar a gaguez (e, através dela, a surdez) poética de muita gente.

SARAIVA, Arnaldo. A Educação (poética) pela Pedra. Correio da Manhã, Rio de Janeiro, p. 2, 27 abr. 1966. 
A. SARAIVA

S. FILUZA

W. Oliveira

A primeira resenha portuguesa sobre A educação pela pedra, de Arnaldo

Saraiva, antecedida por uma apresentação

\section{Referências}

ATHAYDE, Félix (org.). Ideias Fixas de João Cabral de Melo Neto. Rio de Janeiro: Nova Fronteira/FBN; Mogi das Cruzes, SP: Universidade de Mogi das Cruzes, 1998.

COLÓQUIO/LETRAS. Lisboa, n. 157/158, jul./dez. 2000. Paisagem tipográfica: homenagem a João Cabral de Melo Neto.

SARAIVA, Arnaldo. Carta do Brasil. Um grande acontecimento teatral: 'Morte e Vida Severina' de João Cabral de Melo Neto. Jornal de Letras e Artes, Lisboa, p. 5 e 15, 5 jan. 1966.

. A Educação (poética) pela Pedra. Correio da Manhã, Rio de Janeiro, p. 2, 27 abr. 1966.

Dar a ver e a se ver no extremo: o poeta e a poesia de João Cabral de Melo Neto. Porto: CITCEM, Edições Afrontamento, 2014.

STEEN, Edla Van. [Entrevista com João Cabral de Melo Neto]. Viver e escrever. Porto Alegre: L\&PM, 2008. v. 2, p. 11-17.

Submetido em: 12/11/2020

Aceito em: 20/11/2020 